\title{
Fed-Batch Fermentation of L- Threonine by Escherichia Coli Supplemented with B-Vitamins
}

\author{
Yue-wen $\mathrm{SU}^{1}$, Qun-qun GUO ${ }^{1}$, Sen $\mathrm{WANG}^{2}$, Xin $\mathrm{ZHANG}^{2}$ and \\ Jian WANG ${ }^{2, a, *}$ \\ ${ }^{1}$ College of Life Sciences, Jilin University, Changchun, 130022, China \\ ${ }^{2}$ College of Biological and Agricultural Engineering, Jilin University, Changchun, \\ 130022, China \\ awangjian99@jlu.edu.cn \\ ${ }^{*}$ Corresponding author
}

Keywords: Escherichia coli, L-threonine, Fed-batch fermentation, B-vitamins.

\begin{abstract}
B-vitamins can be used as cofactors in the synthesis process of L-threonine. Concentration of the cofactor can effectively change the activity of specific enzymes and reallocate the distribution of carbon substances in the cells. Theeffects of B-vitamins, including calcium pantothenate ( $\left.\mathrm{VB}_{5}\right)$, cobalamin $\left(\mathrm{VB}_{12}\right)$, choline chloride $\left(\mathrm{VB}_{4}\right)$ and nicotinamide $\left(\mathrm{VB}_{3}\right)$, on L-threoninefermentation by fed-batch culture of Escherichiacoli JLTHRin a 5L fermentorwere investigated. The results showed that the production of L-threonine was increased to $133.4 \mathrm{~g} / \mathrm{L}$, which was increased by $7.8 \%$ when supplemented with $1 \mathrm{~g} / \mathrm{L} \mathrm{VB}_{4}$.The production of L-threonine was increased to $130.6 \mathrm{~g} / \mathrm{L}$, which was increased by $5.6 \%$ when supplemented with $10 \mathrm{mg} / \mathrm{L} \mathrm{VB}_{3}$. At last, when a combination of $1 \mathrm{~g} / \mathrm{L} \mathrm{VB} 4$ and $10 \mathrm{mg} / \mathrm{L} \mathrm{VB} 3$ was added to the glucose solutionwith $1.5 \mathrm{~g} / \mathrm{L}$ betainehydrochloride, $138.4 \mathrm{~g} / \mathrm{LL}-$ threonine was accumulated, which was increased by $11.9 \%$.
\end{abstract}

\section{Introduction}

L-threonine is one of the eight essential amino acids of human and animals. It has important physiological functions and significance and can promote human growth and restore human fatigue [1]. Threonine is the fourth most important amino acid following lysine, methionine and tryptophan, and widely used in medical, food, feed and other industries. Thus, the microbial fermentation of L-threonine has been the focus of many researches and developments through strain improvement and fermentation process optimization. [1, 2]A mutant $E$. coli HS3 strains was isolated in which aspartokinase was released from end-product inhibition. The concentrations of the carbon source and the nitrogen source were optimized to improve the production of L-threonine.[3] The fed-batch culture system by adding biotin and oxygen-enriched air to basal minimal salt medium was applied in L-threonine production using the $E$. coli MT201 strain and a production of threonine (80.2 g/L) was achieved.[4] Okamoto established an process for L-threonine fermentation with addition of $\mathrm{D}, \mathrm{L}$-methionine and iron by an L-methionine autotrophic E. coli mutant and achieved a final titer of $101 \mathrm{~g} / \mathrm{L}$ of threonine. [3] Various fermentation substrates and conditions were investigated by $E$. coli TRFC strain. Sucrose was found to be the optimal initial carbon source and glucose was selected as the optimal feeding medium for L-threonine production. [5]

L-Threonine is biosynthesized through the glycolysis pathway, tricarboxylic acid cycle, and the threonine synthesis pathway from glucose. In this metabolic process, a 
number of key enzymes play crucial roleson L-threonine synthesis.Vitamins are a group of trace organic substances, which are essential for microorganism growth and metabolism. They are needed as enzyme cofactors involved in reactions essential for cellular functions. Concentration of the coenzyme factor can effectively change the activity of specific enzymes and reallocate the distribution of carbon substances in the cells. Therefore, cofactor regulation is a highly efficient mean in the microbial metabolic regulation.B-vitamins, choline chloride, etc. can be used as cofactors in the synthesis process of L-threonine. The effects of B-vitamins on L-threonine production by $E$. coli have not yet been systematically investigated so far. In this study, the effects of $\mathrm{VB}_{5}, \mathrm{VB}_{12}, \mathrm{VB}_{3}$ and $\mathrm{VB}_{4}$ on the fermentation of L-threonine were investigated.

\section{Materials and Methods}

\section{Strains and Materials}

Escherichiacoli JLTHR, Jilin University Laboratory for preservation of bacteria.

\section{Medium}

The seed medium contained the following components(per liter of deionized water): glucose $35 \mathrm{~g}$, corn syrup $30 \mathrm{~mL}$, yeast extract $3 \mathrm{~g}, \mathrm{MgSO}_{4} \cdot 7 \mathrm{H}_{2} \mathrm{O} 0.5 \mathrm{~g}, \mathrm{MnSO}_{4} 10 \mathrm{mg}$, $\mathrm{FeSO}_{4} \cdot 7 \mathrm{H}_{2} \mathrm{O} 10 \mathrm{mg}, \mathrm{KH}_{2} \mathrm{PO}_{4} 1.5 \mathrm{~g}$, citric acid $2.0 \mathrm{~g}$, ammonium sulfate 2.0g, $\mathrm{pH} 7.0$, $115^{\circ} \mathrm{C}, 15 \mathrm{~min}$.

Fermentation medium contained the following components(per liter of deionized water) :glucose $20 \mathrm{~g}, \mathrm{MnSO}_{4} 10 \mathrm{mg}, \mathrm{MgSO}_{4} \cdot 7 \mathrm{H}_{2} \mathrm{O} 1.0 \mathrm{~g}, \mathrm{FeSO}_{4} \cdot 7 \mathrm{H}_{2} \mathrm{O} 30 \mathrm{mg}, \mathrm{KH}_{2} \mathrm{PO}_{4}$ $2.0 \mathrm{~g}$, citric acid $1.0 \mathrm{~g}$, corn syrup $12 \mathrm{~mL}$, betainehydrochloride $0.5 \mathrm{~g}, \mathrm{pH} 7.0,115^{\circ} \mathrm{C}$, $15 \mathrm{~min}$.

\section{Culture Method}

Sterile deionized water of $200 \mathrm{~mL}$ was introduced into the slant medium, and the bacteria on the slant were washed off and inoculated into a $5 \mathrm{~L}$ fermentor with a liquid working volume of 2.8 Lat $37^{\circ} \mathrm{C}$. The $\mathrm{pH}$ was adjusted to 7.0 with $25 \%$ (v/v) ammonia. The dissolved oxygen (DO) level was maintained at approximately $20 \%$ $-35 \%$ saturation by adjusting the agitation and aeration rates. The culture grown in the seed fermenter was inoculated aseptically $[15 \%,(\mathrm{v} / \mathrm{v})]$ into $3 \mathrm{~L}$ of production medium in a $5 \mathrm{~L}$ fermenter. The temperature and dissolved oxygen (DO) level were maintained at $37{ }^{\circ} \mathrm{C}$ and $20 \% \sim 35 \%$. The $\mathrm{pH}$ was adjusted to7.0. Once the initial $20 \mathrm{~g} / \mathrm{L}$ of glucose was consumed, $800 \mathrm{~g} / \mathrm{L}$ of glucosesolution with $1.5 \mathrm{~g} / \mathrm{Lb}$ etainehydrochloride and different B-vitamins was continuously fed into the fermenter. $0.2 \mathrm{mg} / \mathrm{L}$ or $10 \mathrm{mg} / \mathrm{LVB}_{5}$, $0.2 \mathrm{mg} / \mathrm{L}$ or $50 \mathrm{mg} / \mathrm{L} \quad \mathrm{VB}_{12}, \quad 10 \mathrm{mg} / \mathrm{L} \quad \mathrm{VB}_{3}, \quad 1 \mathrm{~g} / \mathrm{LVB}_{4}, \quad$ or the combined B-vitaminssolution was added in $800 \mathrm{~g} / \mathrm{L}$ of glucose solutionrespectively with $1.5 \mathrm{~g} / \mathrm{Lbetainehydrochloride} \mathrm{depending} \mathrm{on} \mathrm{the} \mathrm{experiment.}$

\section{Analytical Techniques}

The DO, $\mathrm{pH}$ and temperature were measured automatically with electrodes attached to the fermenters. The culture samples were diluted with $0.15 \mathrm{MNaCl}$, and the optical density was measured at $600 \mathrm{~nm}$ with a spectrophotometer. The concentration of glucose was monitored by an SBA-40 E biosensor analyzer (Biology Institute of Shandong Academy of Sciences, China).The concentration of L-threonine in fermentation broth was determined according to the method of Wang et al.[6] 


\section{Results and Discussion}

\section{Effects of Calcium Pantothenate $\left(\mathrm{VB}_{5}\right)$ on L-threonine Fed-Batch Fermentation}

Calcium pantothenate is the component of $\mathrm{NAD}, \mathrm{NADH}_{2}, \mathrm{NADP}$ andNADPH $\mathrm{N}_{2}$ and the most important hydrogen carrier of biological oxidation, which plays the role of hydrogen transfer. $\mathrm{VB}_{5}$ of $0.2 \mathrm{mg} / \mathrm{L}$ and $10 \mathrm{mg} / \mathrm{L}$ were added to the glucose solution with $1.5 \mathrm{~g} / \mathrm{Lbetainehydrochloride} \mathrm{respectively} \mathrm{to} \mathrm{test} \mathrm{the} \mathrm{effects} \mathrm{of} \mathrm{VB}_{5} \mathrm{On} \mathrm{L}$ - threonine fermentation by E.coliJLTHR.

According to the Fig.1, OD was increased to 58.7 and 63.4 , feeding with $0.2 \mathrm{mg} / \mathrm{L}$ and $10 \mathrm{mg} / \mathrm{L} \mathrm{VB}_{5}$, respectively. It indicated that $\mathrm{VB}_{5}$ was conducive to cell growth. However, the productions of L-threonine feeding with different concentration of $\mathrm{VB}_{5}$ were similar. It proved that $\mathrm{VB}_{5}$ had little effect on L-threonine synthesis pathway.

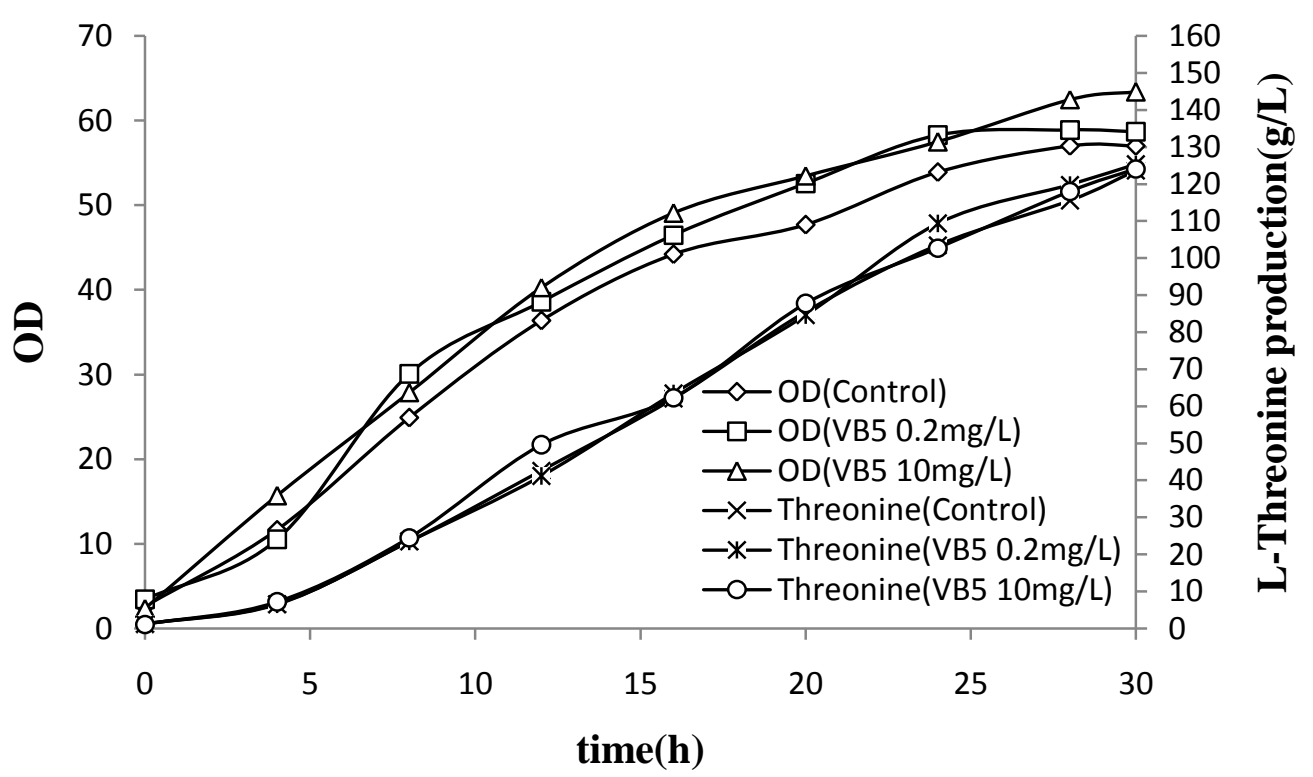

Figure 1. Effects of $\mathrm{VB}_{5}$ on L-threonine fed-batchfermentation

\section{Effects of Cobalamin $\left(\mathrm{VB}_{12}\right)$ on L-threonine Fed-Batch Fermentation}

Cobalamin is a structurally complex cofactor, consisting of a modified tetrapyrrolewitha centrally chelated cobalt. Cobalamin is usually found in one of two biologically active forms: methylcobalamin and adenosylcobalamin. Most prokaryoteshave cobalamin-dependent enzymes. Inbacteria, these enzymes include methioninesynthase, ribonucleotide glutamate and methylmalonyl-CoAmutases, ethanolamine ammonia-lyase, and diol dehydratase.[7] $\mathrm{VB}_{12}$ can transfer methyl to provide a common unit of carbon for the biotransformation, in order to facilitate the synthesis of a variety of cell substances. High concentration of $\mathrm{VB}_{12}$ can effectively improvethe methyl-malonyl CoA isomerase activity, through the isomerization of succinyl-CoA, and enter the tricarboxylic acid cycle route, thus can effectively improve the efficiency of the citric acid cycle and improve the yield of oxaloacetate.

To test the effects of $\mathrm{VB}_{12}$ on L- threonine fermentation by E.coliJLTHR, $\mathrm{VB}_{12}$ of $50 \mathrm{mg} / \mathrm{L}$ and $0.2 \mathrm{mg} / \mathrm{Lwere}$ added to the glucose solution with $1.5 \mathrm{~g} /$ Lbetainehydrochloride, respectively. As shown in Fig.2, the OD on supplementation of $0.2 \mathrm{mg} / \mathrm{L} \mathrm{VB}_{12}$ was up to 62.6 , which was higher than thatof feeding with $50 \mathrm{mg} / \mathrm{LVB}_{12}$. It indicated that low concentration of $\mathrm{VB}_{12}$ was beneficial to the growth of cells. At low concentrations of $\mathrm{VB}_{12}$, it could effectively participate in DNA 
synthesis and metabolism of carbohydrates etc. to increase biomass. However, the productions of L-threonine feeding with different concentration of $\mathrm{VB}_{12}$ were similar. The supplementation of $\mathrm{VB}_{12}$ wasnot contributed to a higher concentration of Lthreonine compared to that feeding with betainehydrochloride only.

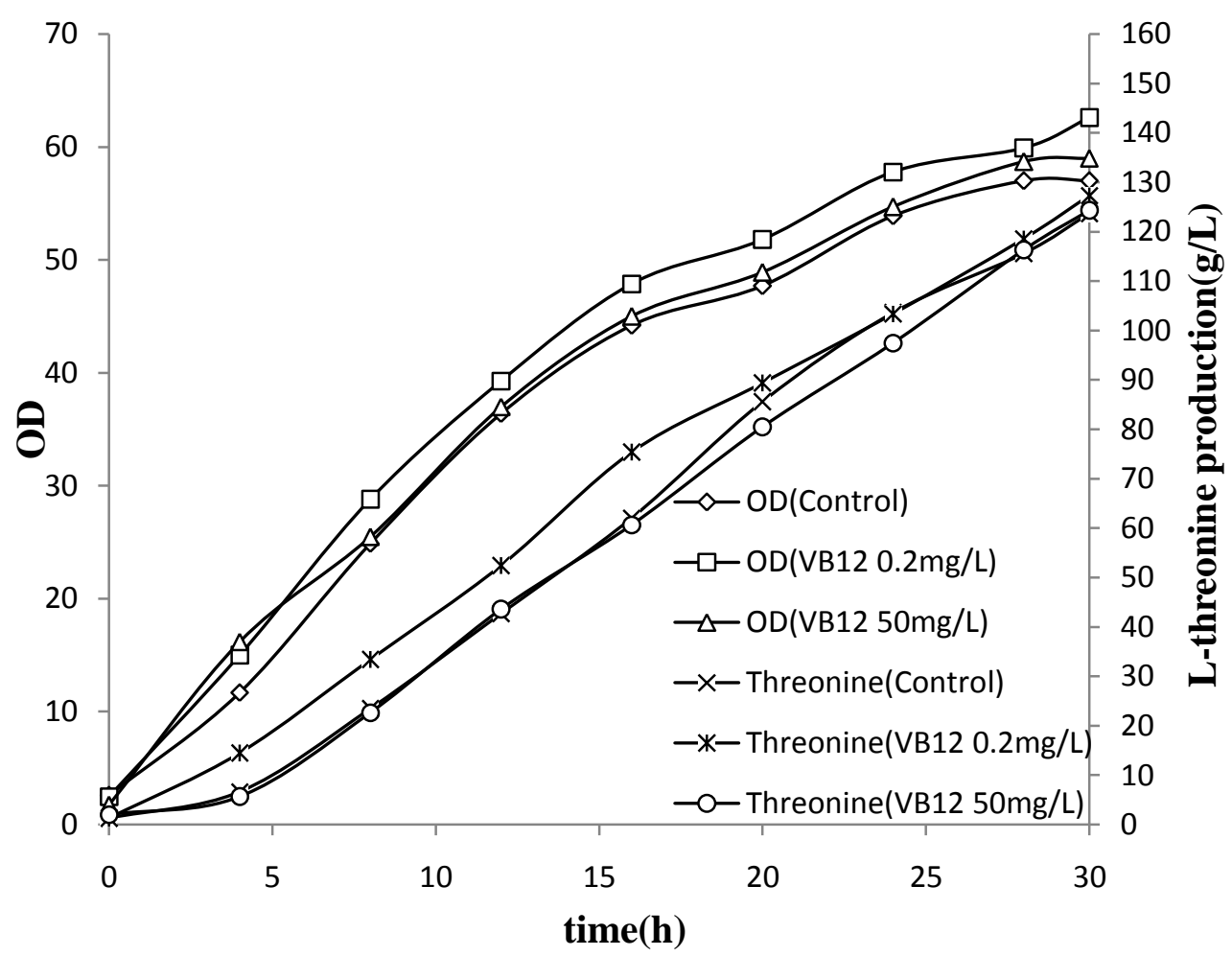

Figure 2. Effects of $\mathrm{VB}_{12}$ on L-threonine fermentation

\section{Effects of Nicotinamide ( $\left.\mathrm{VB}_{3}\right)$ on L-threonine Fed-batch Fermentation}

To test the effects of nicotinamideon L- threonine fermentation by E.coliJLTHR, $\mathrm{VB}_{3}$ of $50 \mathrm{mg} / \mathrm{L}$ and $0.2 \mathrm{mg} / \mathrm{L}$ were added to the glucose solution with $1.5 \mathrm{~g} / \mathrm{L}$ betainehydrochloride, respectively.

According to Fig. 3, not only OD but also the production of $\mathrm{L}$ - threonine was increased feeding with $\mathrm{VB}_{3}$. The titer of $\mathrm{L}$ - threonine reached $130.6 \mathrm{~g} / \mathrm{L}$ feeding with $10 \mathrm{mg} / \mathrm{L} \mathrm{VB} 3$, which was $5.6 \%$ higher than that of feeding with betainehydrochloride only. The titer of $\mathrm{L}$ - threonine reached $126.4 \mathrm{~g} / \mathrm{L}$ feeding with $2 \mathrm{mg} / \mathrm{L} \mathrm{VB}_{3}$, which was $2.2 \%$ higher than that of feeding with betaine hydrochloride only. $\mathrm{VB}_{3}$ is an important component of coenzyme I and coenzyme II. It plays an important role in the glycolysis pathway and participates in the intracellular oxidation process. Therefore, $\mathrm{VB}_{3}$ can effectively improve the growth of bacteria, and increase the production of L-threonine. 


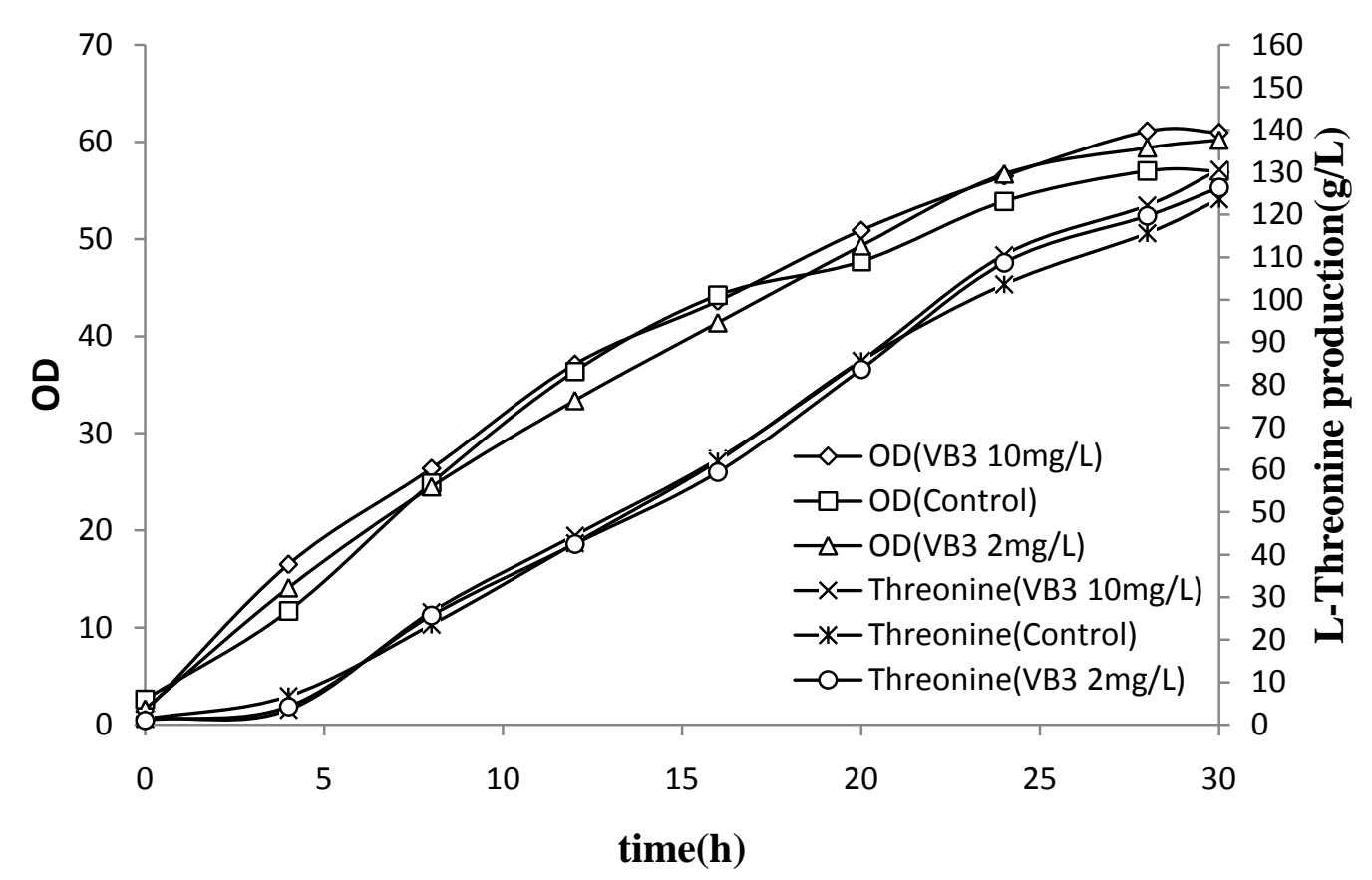

Figure 3. Effects of $\mathrm{VB}_{3}$ on L-threonine fed-batchfermentation

\section{Effects of Choline Chloride ( $\left.\mathrm{VB}_{4}\right)$ on L-threonine Fed-batch Fermentation}

To test the effect of choline chlorideon L- threonine fermentation by E.coliJLTHR, choline chloride of $1 \mathrm{~g} / \mathrm{Lwere}$ added to the glucose solutionwith $1.5 \mathrm{~g} / \mathrm{L}$ betainehydrochloride.

As shown in Fig.4, addition of choline chloride not only increased OD, but also improved L-threonine production greatly. The production of L-threonine achieved 133.4g/L.Choline is an important component of lecithin, used to constitute the cell membrane and promote cell physiological metabolism, and thus can promote cell growth.E.coliis extensively used as a host for producing L-threonine. However, it is challenged by highsalt concentration in the fermentation broth.The osmotic stress triggered by high salt concentration results in both structural and physiological injury of cells. Choline chloride is a synthetic precursor of betaine. Itcan act as stress protectant or methyl donor for the biosynthesis of structurally complex compounds. Moreover, Choline chloride can protect the activity of enzymes associated with L-threonine synthesis.In addition, because choline chloride can increase the mobility of the cell membrane, it is conducive to the output of L-threonine. 


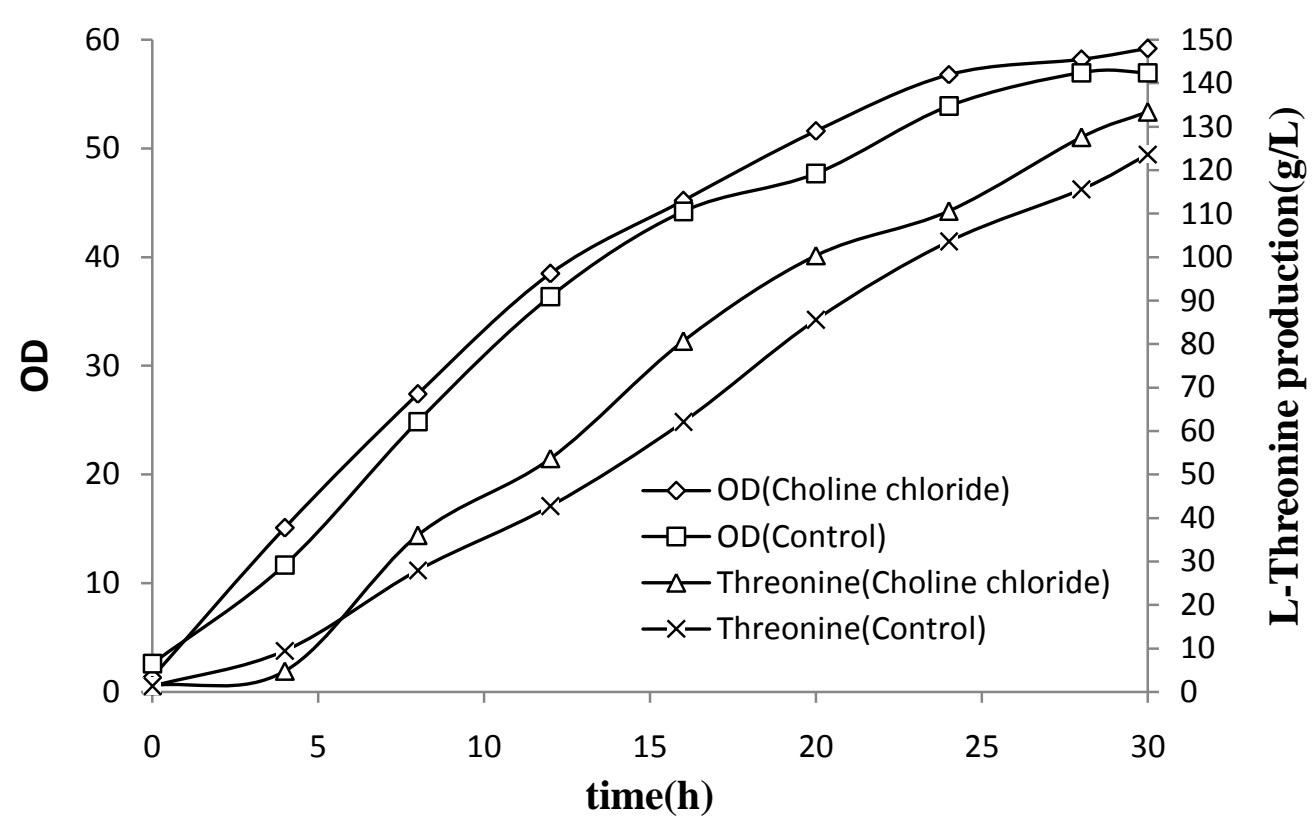

Figure 4. Effects of choline chloride on L-threonine fed-batchfermentation

\section{Effects of Combined B-vitamins on L-threonine Fed-batch Fermentation}

Since the supplementation of $\mathrm{VB}_{3}$ and $\mathrm{VB}_{4}$ had contributed to a higher concentrationof L- threonine, the combined B-vitamins solution of $10 \mathrm{mg} / \mathrm{L} \mathrm{VB} 3$ and $1 \mathrm{~g} / \mathrm{LVB}_{4}$ was added to the glucose solutionwith $1.5 \mathrm{~g} / \mathrm{L}$ betainehydrochloride. As shown in Fig.5,in the early stage of fermentation, the growth of E.coliJLTHRwas not much different with the control. But with the rapid growth of E.coliJLTHR, it began to produce more metabolites, thus the growth difference was gradually shown up. OD supplemented with $\mathrm{VB}_{3}$ and $\mathrm{VB}_{4}$ was increased to 61.5. The addition of $\mathrm{VB}_{3}$ and $\mathrm{VB}_{4}$ compound has an $11.9 \%$ increase in production of L-threonine $(138.4 \mathrm{~g} / \mathrm{L})$ compared with feeding with betaine hydrochloride only.

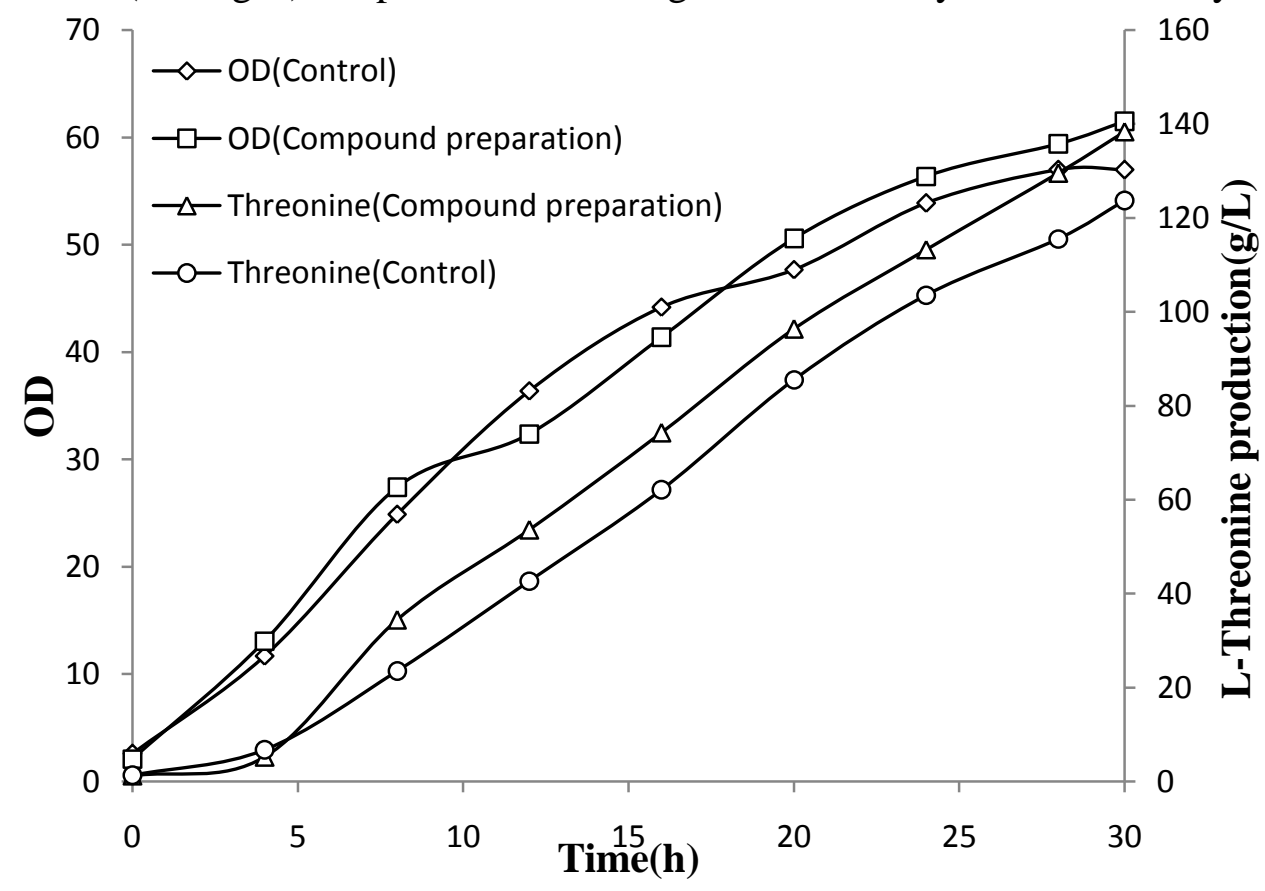

Figure 5. Effects of Combined B-vitamins on L-threonine fed-batchfermentation 


\section{Conclusions}

Since vitamins are essential for microorganism growth and metabolism, the effects of supplying B-vitamins on L-threonine fed-batchfermentation were intensivelystudied in this work. The L-threonine production of adding $1 \mathrm{~g} / \mathrm{LVB}_{4}$ in glucose solution with $1.5 \mathrm{~g} /$ Lbetainehydrochloridereached $133.4 \mathrm{~g} / \mathrm{L}$, which was the highest among that of supplying B-vitamins. The L-threonine production of adding $10 \mathrm{mg} / \mathrm{L} \mathrm{VB} 3$ in glucose solution with $1.5 \mathrm{~g} / \mathrm{L}$ betainehydrochloride was increased to $130.6 \mathrm{~g} / \mathrm{L}$, which was higher than that of supplying $\mathrm{VB}_{12}$ and $\mathrm{VB}_{5}$. At last, the highest L-threonine production of $138.4 \mathrm{~g} / \mathrm{L}$ was obtained by fed with glucose solution containing $1.5 \mathrm{~g} / \mathrm{L}$ betaine hydrochloride, $10 \mathrm{mg} / \mathrm{L} \mathrm{VB}_{3}$ and $1 \mathrm{~g} / \mathrm{LVB}_{4}$.

To additionally improve L-threonine production by E. coliJLTHR, further studies are needed by optimization of the fermentation process and construction of new strains.

\section{Acknowledgement}

This research was financially supported by the National High Technology Research and Development Program of China (Grant No. 2015AA021003).

\section{References}

[1] Debabov VG. The threonine story.AdvBiochemEngBiotechnol. 79(2003) 113-136.

[2] KranerR. Genetic and physiological approaches for the production of aminoacids.J Biotechnol. 45(1996)1-21.

[3] Okamoto K, Ikeda M. Development of an industrially stable process for L-threonine fermentation by an L-methionine-auxotrophic mutant of Escherichia coli. J Biosci Bioeng. 89(2000) 87-89.

[4] Lee MH, Lee HW, Park JH, Ahn JO, Jung JK, Hwang YI. Improved L-threonine production of Escherichia coli mutant by optimization of culture conditions.J BiosciBioeng. 101(2006) 127-130.

[5] Chen N, Huang J, Feng ZB, Yu L, Xu QY, Wen TY. Optimization of fermentation conditions for the biosynthesis of L-threonine by Escherichia coli. ApplBiochemBiochem. 158(2009) 595-604.

[6] Wang J., Cheng LK., Chen N. High-level production of L-threonine by recombinantEscherichia coli with combined feeding strategies. Biotechnology Biotechnological Equipment.28(2014) 495-501.

[7] Rodionov DA, Vitreschak AG, Mironov AA, Gelfand MS. Comparative genomics of the vitamin $B_{12}$ metabolism and regulation in prokaryotes. J. Biol. Chem.278 (2003) 41148-59. 